of about $100 \times 40$ feet ground area, and of two stories. The exterior will be simple and unpretentious. The building will be placed close to the sea-shore, so that sea water can be readily pumped into the laboratory tank, and in order that there may be easy communication with fishing-boats. It will also be desirable to have a floating barge anchored near the laboratory for special experiments on the breeding of fish, \&ce, and, in close proximity, it will be necessary to erect tanks on the foreshore, open to the tidal water, but arranged so as to prevent the escape of the animals confined in them for study.

The basement of the building will contain a reservoir tank holding several thousand gallons of sea water; on the ground floor there will be two large rooms paved with stone; one fitted with large tanks and a service of sea water, the other used for the reception and examination of a day's trawling or dredging, and also used for keeping stores and for carrying out the pickling and proper preservation of specimens to be sent, as required, to naturalists at a distance. The upper floor will be divided into a series of larger and smaller working rooms fitted with suitable tables, with reagents and apparatus required in microscopy, and with a constant supply of sea water pumped from the reservoir tank. Accommodation for ten workers will be thus provided. One of the rooms on this floor must be set apart as a library and writing room, and must contain as complete a series of works on marine zoology and botany, pisciculture, and such matters as can be brought together. The provision of such a library is one of the special conveniences which would be offered to naturalists working in the laboratory.

The building must also necessarily contain bed-room and sitting-room for a resident superintendent, and accommodation for one servant or caretaker.

2. Apparatus and Boats. - These need not at first be very extensive. Glass tanks, pumping engine and supply tubes are essential. There will be necessarily one small steam-launch for dredging in quiet weather at no great distance from shore, and a row-boat. For special expeditions larger boats or steamers could be either hired or borrowed from time to time. The local fishermen would also greatly aid the laboratory if regularly paid, and thus supplement the special boats of the Association.

3. Salaried Staff.-The Council would propose to begin work with the smallest possible number of permanent employés. These would be- $(a)$ a resident superintendent, who should be a man of fair education and some knowledge of natural history, at a salary of $\mathbf{I} 50 \%$. a year, supplemented by free quarters; $(b)$ a servant of the fisherman class, who would look after the tanks and workrooms, go out in search of specimens, and manage a boat and dredging apparatus when required. Other fishermen and boys might be hired from time to time. A sum of 100l. a year would be required for such service at the least.

4. Conditions of Admission to Use of Laboratory: Work to be done there.-The Council would propose to admit to the use of a table and other resources of the laboratory, so far as the space shall permit, any British or foreign naturalist who might make application and furnish evidence of his capability to make good use of the opportunities of the place. A preference would be given to a member of the Association, A fee might in some cases be charged for the use of a table, and other tables might be let out at an annual rental to such bodies as the Universities, this being the system adopted at Naples by Dr. Dohrn.

The Council will endeavour, when the laboratory is erected and in operation, to obtain grants of money from scientific societies, and from the Covernment, for the purpose of carrying out special investigations on a given subject, e.g., the condition affecting the fall of oyster-spat, the reproduction and general economy of the common sole, the complete determination and enumeration of the fauna and flora of the marine area adjacent to the site of the laboratory, its distribution within that area, and its relation to physical conditions. Naturalists will be nominated by the Council of the Association or by the authorities who find the money by which such naturalists are paid, to make such researches at the laboratory of the Association. When some special investigation is thus started at the laboratory, the other naturalists, who from time to time come there, will be sure to take part in the inquiry, and so help to carry it on to completion. It would be the business of the resident superintendent to facilitate this continuity of work, whilst the Council of the Association will make it a special object to bring together the results attained in the laboratory each year, in the form of a report, so as to gradually organise and direct towards definite ends the work done through its agency.
In the course of time, and with increased provision of funds for the special purpose, the Association might expect to be the means of producing -

I. A thorough knowledge of the life and conditions of the marine area adjacent to the laboratory.

2. A complete and detailed account of the natural history of certain fishes, molluscs, and crustaceans of economic importance with special reference to their increased supply.

3. Contributions to the knowledge of the growth from the egg, adult structure and physiology of such rare or otherwise scientificially interesting animals and plants as occur near the laboratory.

It is not supposed that this can be immediately accomplished by the 10,000 l. which the Association now seeks to raise. That sum will be expended in erecting the laboratory and in starting it on its career of activity. The laboratory will necessarily attract support and increased means of usefulness as, year by year, its work becomes known, and the facilities which its offers to working naturalists appreciated.

Signed (by order of the Council of the

Marine Biological Association),

July 25

E. Ray Lankester, M.A., F.R.S., Hon. Secretary

\section{THE METEOROLOGICAL CONFERENCE}

A METEOROLOGICAL conference was held at the Health Exhibition on July 17 and 18 ; the following is an abstract of the leading papers read at the conference.

Dr. J. W. Tripe read a paper of much interest on some relations of meteorological phenomena to health.

In ages long past these relations excited much attention, but the knowledge concerning them was of the vaguest kind ; and indeed, even now, no very great advance has been made, because it is only quite recently that we have been able to compare a fairly accurate record of deaths with observations taken at a number of reliable meteorological stations. The more useful and searching comparison between cases of sickness, instead of deaths, and meteorological phenomena has yet to be accomplished on a large scale in this country, and especially as regards zymotic diseases. In Belgium there is a Society of Medical Practitioners, embracing nearly the whole country, that publishes a monthly record of cases of sickness, of deaths, and of meteorological observations; but the only attempt on a large, scale in this country, which was started by the Society of Medical Officers of Health for the whole of London, failed partly from want of funds, and partly from irregularity in the returns. My remarks, which must necessarily be very brief, will refer to the relations between ( $r$ ) meteorological phenomena and the bodily functions of man, and (2) between varying meteorological conditions and death-rates from certain diseases.

As regards the first, I will commence with a few brief remarks on the effects of varying barometric pressures. A great deal too much attention is paid to the barometer if we regard it as indicating only, as it really does, variations in the weight of the column of air pressing upon our bodies, because, except at considerable elevations, where the barometer is always much lower than at sea-level, these variations produce but little effect on health. At considerable elevations the diminished pressure frequently causes a great feeling of malaise, giddiness, loss of strength, palpitation, and even nauser; and at greater heights, as was noticed by $\mathrm{Mr}$. Glaisher in a very lofty balloon ascent, loss of sight, feeling, and consciousness. These were caused by want of a sufficient supply of oxygen to remove effete matters from the system, and to carry on the organic functions necessary for the maintenance of life. On elevated mountain plateaus, or even in high residences amongst the Alps, an increased rapidity in the number of respirations and of the pulse, as well as increased evaporation from the lungs and skin, occur.

For some years past, many persons suffering from consumption, gout, rheumatism, and anemic affections have gone to mountain stations, chiefly in Switzerland, for relief, and many have derived much benefit from the change. It must not however, be supposed that diminished atmospheric pressure was the chief cause of the improvement in health, as its concomitants, viz., a diminution in the quantity of oxygen and moisture contained in each cubic foot of air, probably the low temperature, with a 
total change in the daily habits of life, have assisted in the beneficial results. The diminution in the quantity of air, and consequently of oxygen, taken in at each breath is to a certain extent counterbalanced by an increased frequency and depth of the respirations, and a greater capacity of the chest. In this country, alterations in the barometric pressure are chiefly valuable as indicating an approaching change in the wind, and as well as of the amount of moisture in the air ; hence the instrument is often called "the weather glass." A sudden diminution in the atmospheric pressure is likely to be attended with an escape of ground air from the soil, and therefore to cause injury to health, especially among th the occupants of basement rooms, unless the whole interior of the building be covered with concrete.

Temperature.-Experience has shown that man can bear greater variations of temperature than any other animal, as in the Arctic regions a temperature of 70 degrees Fahrenheit, or more than too degrees below freezing-point, can be safely borne; that he can not only live but work, and remain in good health in these regions, provided that he be supplied with suitable clothing and plenty of proper food. On the other hand, man has existed and taken exercise in the interior of Australia, when the thermometer showed a temperature of 120 degrees Fahrenheit, or nearly 90 degrees above freezing-point, so that he can live and be in fairly good health within a range of nearly 200 degrees Fahrenheit.

The effects of a high temperature vary very much according to the amount of moisture in the air, as when the air is nearly saturated in hot climates, or even in summer in our own, more or less languor and malaise are felt, with grcat indisposition to bodily labour. With a dry air these are not so noticeable. The cause is evident; in the former case but little evaporation occurs from the skin, and the normal amount of moisture is not given off from the lungs, so that the body is not cooled down to such an extent as by dry air. Sunstroke is probably the result, not only of the direct action of the sun's rays, but partly from diminished cooling of the blood by want of evaporation from the lungs and skin.

The effects of temperature on man does not depend so much on the mean for the day, month, or year, as on the extremes, as when the days are hot and the nights comparatively cool, the energy of the system becomes partially restored, so that a residence near the sea, or in the vicinity of high mountains, in hot climates is, other things being equal, less enervating than in the plains, as the night air is generally cooler. It is commonly believed that hot climates are necesiarily injurious to Europeans, by causing frequent liver derangements and diseases, dysentery, cholera, and fevers. This, however, is, to a certain extent, a mistake, as the recent medical statistical returns of our army in India show that in the new barracks, with more careful supervision as regards diet and clothing, the sickness and death-rates are much reduced. Planters and others, who ride about a good deal, as a rule keep in fairly good health; but the children of Europeans certainly degenerate, and after two or three generations die out, unless they intermarry with natives, and make frequent visits to colder climates. 'This fact shows that hot climates, probably by interfering with the due performancc of the various processes concerned in the formation and destruction of the bodily tissues, eventually sap the foundations of life amongst Europeans; but how far this result has been caused by bad habits as regards food, exercise, and selfindulgence, I cannot say. Rapid changes of temperature in this country are often very injurious to the young and old, causing diarrhœea and derangements of the liver when great heat occurs, and inflammatory diseases of the lungs, colds, \&c., when the air becomes suddenly colder, even in summer.

The Direct influence of rain on man is not very marked in this country, except by giving moisture to the air by evaporation from the ground and from vegetable life, and by altering the level of ground water. This is a subject almost overlooked by the public, and it is therefore as well that it should be known that when ground water has a level, persistently less than five feet from the surface of the soil, the locality is usually unhealthy, and should not, if possible, be selected for a residence. Fluctuations in the level of ground water, especially if great and sudden, generally cause ill-health amongst the residents. Thus, Dr. Buchanan in his Reports to the Privy Council in $1866-67$, showed that consumption (using the word in its most extended sense) is more prevalent in damp than on dry soils, and numerous reports of medical officers of health, and others, which have been published since then, show that an effective drainage of the land, and consequent carrying away of the ground water has been followed by a diminution of these diseases.

Varying amounts of moisture in the air materially affect the health and comfort of man. In this country, however, it is not only the absolute but the relative proportions of aerial moisture which materially influence mankind. The quantity of aqueous vapour that a cubic foot of air can hold in suspension, when it is saturated, varies very much with the temperature. Thus at 40 degrees Fahr. it will hold 2.86 grains of water; at 50 degrees, $4^{\circ}$ Io grains; at 60 degrees, 5.77 grains; at 70 degrees, $8 \cdot 0$ r grains ; and at 90 degrees as much as $\mathrm{I}_{4} .85$ grains. If saturation be represented by 100 , more rapid evaporation from the skin will take place at 70 degrees, and 75 per cent. of saturation, than at 60 degrees when saturated, although the absolute quantity of moisture in the air is greater at the first-named temperature than at the latter. As regards the lungs, however, the case is different, as the air breathed out is, if the respirations be regular and fairly deep, completely saturated with moisture at the temperature of the body. In cold climates the amount of moisture and of the effete matters given off from the lungs in the expired air, is much greater than in hot climates, and the body is also cooled by the evaporation of water in the form of aqueous vapour. Moist air is a better conductor of heat than dry air, which accounts for much of the discomfort felt in winter when a thaw takes place as compared with the feeling of elasticity when the air is dry. In cold weather, therefore, moist air cools down the skin and lungs morc rapidly than dry air, and colds consequently result. London fogs are injurious, not only on account of the various vapours given off by the combustion of coal, but in consequence of the air being in winter generally saturated with moisture at a low temperature. The injuriousness of fogs and low temperatures will be presently dwelt upon at greater length.

Variations in the pressure and temperature of the atmosphere exert a considerable influence on the circulation of air contained in the soil, which is called ground air. As all the interstices of the ground are filled with air or water, the more porous the soil, the greater is the bulk of air. The quantity of ajr contained in soil varies very much according to the material of which the soil is composed, as it is evident that in a gravelly or sandy soil it must be greater than when the ground consists of loam or clay. The estimates vary from 3 to 30 per cent., but the latter is probably too high. If, therefore, a cesspool leak into the ground, the offensive effluvia, if in large quantities, will escape into the soil, and are given off at the surface of the ground, or are drawn into a house by the fire; but, if small, they are rendered inocuous by oxidation. The distance to which injurious gases and suspended or dissolved organic matters may travel through a porous soil is sometimes considerable, as I have known it pass for $\mathbf{I} 30$ feet along a disused drain, and above 30 feet through loose soil.

Winds exercise a great effect on health both directly and indirectly. Directly, by promoting evaporation from the skin, and abstracting heat from the body in proportion to their dryness and rapidity of motion. Their indirect action is more important as the temperature and and pressure of the air depend to a great extent in their direction. Thus winds from the north in this country are usually concomitant with a high barometer and dry weather; in summer with a pleasant feeling, but in winter with much cold. South-west winds are the most frequent here of any, as about 24 per cent. of the winds come from this quarter against $16 \frac{1}{2}$ from the west, $11 \frac{1}{3}$ from the east, and the same from the north-east; $10 \frac{1}{2}$ from the south, 8 from the north, and a smaller number from the other quarters. South-west winds are also those which are most frequently accompanied by rain, as about 30 per cent. of the rainy days are coincident with south-west winds. Another set of observations give precisely the same order, but a considerable difference in their prevalence, viz. south-west $3 \mathrm{I}$ per cent, west $14 \frac{1}{2}$, and north-east II $\frac{1}{2}$ per cent. Easterly winds are the most unpleasant, as well as the most injurious to man of all that occur in this country.

I now propose discussing very briefly the known relations between meteorological phenomena and disease. I say the known relations, because it is evident that there are many unknown relations of which at present we have had the merest glimpse. For instance, small-pox, while of an ordinary type, and producing only a comparatively small proportion of deaths to those attacked, will sometimes suddenly assume an epidemic form, and spread with great rapidity at a time of year and under the meteorological conditions when it usually declines in fre- 
quency. There are, however, in this country known relations between the temperature and, I may say, almost all diseases. As far back as 1847 I began a series of elaborate investigations on the mortality from scarlet fever at different periods of the year, and the relations between this disease and the heat, moisture, and electricity of the air. I then showed that a mean monthly temperature below $44^{\circ} \cdot 6 \mathrm{~F}$. was adverse to the spread of this disease, that the greatest relative decrease took place when the mean temperature was below $40^{\circ}$, and that the greatest number of deaths occurred in the months having a mean temperature of between $45^{\circ}$ and $57^{\circ} \mathrm{F}$. Diseases of the lungs, excluding consumption, are fatal in proportion to the lowness of the temperature and the presence of excess of moisture and fog. Thus, in January I 882 the mean weekly temperature fell from $43^{\circ} \cdot 9 \mathrm{~F}$. in the second week to $36^{\circ} \cdot 2$ in the third, with fog and mist. The number of deaths registered in London during the third week, which may be taken as corresponding with the meteorological conditions of the second week, was I7oo, and in the next week 197I. Unusual cold, with frequent fogs and little sunshine, continued for four weeks, the weekly number of deaths rising from 1700 to $197 \mathrm{I}, 2023,2632$, and 2188 . The death from acute diseases of the lungs in these weeks were respectively $279,481,566,881$, and 689 , showing that a large proportion of the excessive mortality was caused by these diseases. At the end of November and in December of the same year there was a rapid fall of temperature, when the number of deaths from acute diseases of the lungs rose from 297 to $358,350,387,54 \mathrm{I}$, 553 , and 389 in the respective weeks. From November 29 to December 9 the sun was seen only on two days. for $4 \frac{1}{2}$ hours, and from December 9 to the 18 th also on two other days for less than 4 hours, making the total amount of sunshine $8 \cdot$ I hours only in 20 days. In January and February the excess of weekly mortality from all diseases reached the large number of 504 deaths; in December it was less, the fogs not having been so dense, but the excess equalled 246 deaths per week.

The relations between a high summer temperature and excessive mortality from diarrhoea have long been well known, but the immediate cause of the disease as an epidemic is not known. Summer diarrhoea prevails to a greater extent in certain localities, notably in Leicester (and has done so for years) ; and the cause has been carefully sought for, but has not been found out. Recent researches, however, point to a kind of bacillus as the immediate cause, as it has been found in the air of water-closets, in the traps under the pans, and in the discharges from infants and young children. In order to indicate more readily how intimately the mortality from diarrhœa depends on temperature, I now lay before you a table showing the mean temperature for ten weeks in summer, of seven cold and hot summers, the temperature of Thames water, and the death-rates of infants under one year per million population of London :-

London. Deaths under I Year, in July, August, and part of September, from Diarrhea per 1,000,000 Population Living at all Ages, arranged in the Order of Mortality

\begin{tabular}{|c|c|c|c|c|c|c|}
\hline Years & & $\begin{array}{c}\text { Mean } \\
\text { temperature, } \\
\text { to weeks } \\
\end{array}$ & & $\begin{array}{l}\text { Temperature } \\
\text { of Thames } \\
\text { water }\end{array}$ & $\begin{array}{r}\text { Deat } \\
\text { p } \\
\text { pop }\end{array}$ & $\begin{array}{l}\text { e o-r year. } \\
\text { sfrom diarrhøa } \\
\text { r, ooo, oso } \\
\text { ation living at } \\
\text { all ages }\end{array}$ \\
\hline 1860 & $\cdots$ & $58^{\circ} \cdot I$ & & $60 \cdot 6$ & $\ldots$ & $\begin{array}{c}\text { all ages } \\
\text { I5I }\end{array}$ \\
\hline 1862 & $\ldots$ & $59^{\circ} \circ$ & $\ldots$ & $620^{\circ}$ & $\ldots$ & 189 \\
\hline 1 879 & $\ldots$ & 58.7 & $\ldots$ & $60 \cdot 7$ & $\ldots$ & 228 \\
\hline I877 & $\ldots$ & $6 \mathrm{I} \cdot 2$ & $\ldots$ & 63.3 & $\ldots$ & 347 \\
\hline$\times 874$ & $\ldots$ & $6 r \cdot 7$ & $\ldots$ & 63.8 & $\ldots$ & 447 \\
\hline 1878 & $\ldots$ & 63.7 & $\ldots$ & $64 \cdot I$ & $\ldots$ & 576 \\
\hline 1876 & $\ldots$ & 64.4 & $\ldots$ & 649 & $\ldots$ & 642 \\
\hline
\end{tabular}

As may be seen, the deaths of infants under I year of age from diarrhøea per $\mathbf{I}, 000,000$ population was only $\mathbf{I} 5 \mathbf{I}$; whilst the mean summer temperature was only $58^{\circ} \cdot \mathrm{I} \mathrm{F}$. against $\mathrm{I} 89$ in 1862 , when the mean temperature was $59^{\circ} \circ$. In 1879 , when the mean temperature was $58^{\circ} \%$, the deaths from diarrhoea rose to 228 per million, but a few days were unusually hot. In 1877 the mean temperature of the air was $61^{\circ} \cdot 2$, of the Thames water $63^{\circ} \cdot 3$, and the mortalityof infants from diarrhœa 347 per million population. In 1874, when the mean temperature of the air was $61^{\circ} \%$, the mortality rose to 447 per million; and in the hot summers of 1878 and 1876 , when the mean air temperatures were $64^{\circ} \cdot 1$ and $64^{\circ} .9$ respectively, the death-rates of infants were 576 and 642 per million population. The relations, therefore, between a high summer temperature and the mortality from diarrhoea in infants are very intimate. I have selected the mortality amongst infants in preference to that at all ages, as the deaths occur more quickly, and because young children suffer in greater proportion than other persons.

The proportionate number of deaths at all ajes from diarrhœea corresponds pretty closely with those of infants. To prove this, I made calculations for three years, and ascertained that only $3^{\circ} 9$. per cent. of all the deaths from this disease were registered in the weeks having a temperature of less than $50^{\circ}$; II 9 per cent. in the weeks having a temperature between $50^{\circ}$ and $60^{\circ}$, whilst in the comparatively few weeks in which the temperature cxceeded $60^{\circ} \mathrm{F}$., as many as $84^{\circ} 2$ per cent. of the total number of deaths was registered. In the sixteen years, $1840-56$, for which many years ago I made a special inquiry, only 18.9 per cent. of all the deaths from diarrhœea occurred in winter and spring, against $8 I^{\prime} I$ per cent. in summer and autumn. In the twenty years, I860-79, there were seven years in which the summer temperature was in defect when the mortality per 100,000 inhabitants of London was 200 ; whilst in ten summers, during which the temperature was in excess by $z^{\circ}$ or less, the mortality was $3 \mathrm{I} 7$ per 100,000 . The mean temperature was largely in excess, that is to say, more than $2^{\circ}$ plus in three of these summers, when the mortality reached 339 per Ioo, ooo inhabitants. These figures show that great care should be taken in hot weather to prevent diarrhœea, especially amongst young children; by frequent washing with soap and water to ensure cleanliness, and proper action of the skin; by great attention to the food, especially of infants fed from the bottle; free ventilation of living rooms, and especially of bedrooms ; and by protection, as far as possible, being afforded from a hot sun, as well as by avoiding excessive exercise. All animal and vegetahle matter should be removed from the vicinity of dwelling-houses as quickly as possible (indeed these should be burnt instead of being put in the dust-bin), the drains should be frequently disinfected and well flushed out, especially when the mean daily temperature of the air is above $60^{\circ} \mathrm{F}$.

Time will not admit of more than a mere mention of the relations between meteorological phenomena and the mortality from many other diseases and affections, such as apoplexy from heat, sunstroke, liver diseases, yellow fever, cholera, whoopingcough, measles, \&c., especially as the state of our knowledge on the subject is so very limited. A comparison between the mortality from several diseases in this and other countries shows that certain of these do not prevail under closely corresponding conditions. Thus the curves of mortality from whooping-cough, typhoid fever, and scarlet fever, do not correspond with the curves of temperature in both London and New York, and the same may be said of diarrhoea in India. It is therefore evident that some other cause or causes than a varying temperature must be concerned in the production of an increased death-rate from these diseases. The subject is of great importance, and I do not despair of our obtaining some day a knowledge of the agents through which meteorological phenomena act in the production of increased and decreased death-rates from certain diseases, and the means by which, to a certain extent, these injurious effects on man be prevented.

Mr. R. H. Scott, F.R.S., read a paper on "The Equinoctial Gales-do they occur in the British Isles?" Most scientific meteorologists, $\mathrm{Mr}$. Scott stated, are disposed to give up, almost in despair, the idea of eradicating from the popular mind the belief in the influence of the moon on the weather. There is, however, another belief, not quite so widely spread, but still very generally accepted, which attributes to the equinoxes a peculiarly stormy character. Over and over again have I heard the remark that it would be well for those proposing to take a voyage to wait until the equinoctial gales were over. It has struck me, therefore, that as we have had for several years past a regular system of storm warnings, it might be of interest to ascertain if the record of these warnings, and of the storm with which they were connected, exhibited any maximum of storm frequency about the equinoxes.

The period I have taken has been that of the fourteen years beginning with the spring of 1870 , and I have commenced with the spring in order to include the past winter, that of $1883-4$. With the year $18 \%$, the systematic checking of storm warnings was commenced on the demand of the late Colonel Sykes. The results were published as "Parliamentary Papers" for the first seven years, and subsequently the returns have been regularly prepared in the Meteorological Office, though only the summary of results has appeared in the Annual Reports. As these returns give not only the storms for which warnings were issued 
but also those for which none were sent out, they afford a ready index to the storms which have been felt on the coasts.

Only such storms have been selected as have been really severe, such as have attained force 9 of the Beaufort scale at more than two stations, with a velocity exceeding 50 miles an hour recorded by an anemograph for more than a single hour. I have also not discriminated between the directions from which the strongest winds were felt.

The results of these records show that gales are of no greater frequency at the equinoxes than at any other time.

The diagrams show that the storms are all but exchusively confined to the winter half-year, if we take that to include part of the autumn and spring.

The diagrams show that there is no strongly-marked maximum at either equinox, but they do exhibit indications of periodicity which are very interesting.

Leaving the summer alone, as not worth notice, the frequency rises from nine and eight in the periods preceding the autumn equinox to ten at that epoch. The curve then rises rapidly, the value doubling itself and trebling itself in the two succeeding intervals. We then find a falling off at the time of the Martinmas summer in the first half of November, and a second maximum in the end of that month-the period indicated by Sir John Herschel long ago, in an article in Good Words for January I864, as that succeeding what he called "The Great November Wave," a phenomenon which does not receive as much attention now as formerly. The first part of December is comparatively quiet, but after that the frequency rises to its absolute maximum at the latter half of January, from which period the curve descends gradually, with one decided check in February, to the same value which it had in August, and which it attains at the end of April. The check in February reminds us of the wellknown tradition of the "halcyon" days at the end of winter. The frequency at the spring equinoctial period is nearly double what it is at the corresponding interval at the autumn equinox, being I9 as compared with Io. In one particular, however, the phenomena agree-the equinoxes are periods of sudden change in storm frequency. In the autumn this rises from 10 to 20 as soon as the equinox is passed; in the spring it falls from 27 to 19 as the equinox arrives. Accordingly, persons who wait till the equinox is passed in autumn improve their chances of falling in with a storm, for the diagram shows no signs of a lull once a heavy storm has occurred. In the spring it would apparently be wise to wait till April was well advanced, if you wished to get calm weather in the Bay of Biscay.

If we now look to see what evidence of recurrence of storms for particular short periods is discoverable in our data, we find that the day most frequently so distinguished is January $\mathbf{I}$, on which a storm was recorded six times in the fourteen years. This is very remarkable, as December $3 \mathbf{I}$ only shows one, and January 2 only two storms. Five days-November 10 and 20 , January 18 and 19 , and February 26-show five each, and no less than sixteen days show four. The stormiest two-day interval is that of January 18 and 19 , which, as just explained, exhibits five storms each. The most disturbed three-day period is that of January 24 to 26 , where we find four storms on each day. The date of the Battle of Trafalgar, October 2I, is marked by two fours, on the 2rst and 22nd, but the end of October is not so disturbed as the end of January.

The diagram also shows that almost every month in the year is occasionally nearly free from storms. October, November, December, and January have only one apiece, but in different years. March is the only month which has at least two storms, thus justifying its epithet, "March many-weathers."

Mr. Scott also read a paper on Cumulative Temperature, of which the following are the leading points :-

On the walls of the Meteorological Annexe will be found a series of diagrams, exhibiting from various districts in the United Kingdom, in a graphical form, the March of Temperature, Rainfall, and Bright Sunshine, from the beginning of the present year, and also for the entire year I881, which is reproduced for purposes of comparison.

The object of these curves is to show clearly some of the most important factors in the growth of crops.

It is proved, almost beyond a doubt, that each plant, say each individual cereal, requires a definite amount of heat to bring it to maturity. Thus, maize requires more than wheat, and wheat again more than barley or oats.

Now various investigators, and notably Boussingault and Prof.
Alphonse de Candolle, of Geneva, have devoted much attention to this subject, and the latter writer, in his "Géographie Botanique," has come to the conclusion that a certain total amount of temperature above a definite base line is necessary for plant growth, and that this amount, or, as he calls it, this "sum of temperature," varies for each crop.

He found that plants, as a rule, did not begin to give indications of active vegetation until the temperature rose above $6^{\circ} \mathrm{C}$. This temperature, $6^{\circ} \mathrm{C}$., or, in round numbers, $42^{\circ} \mathrm{F}$, that is ten degrees above the freezing point, is taken as the base for all the diagrams. Although Prof. de Candolle propounded his views some years ago, as recently as the year 1874 , at the Agricultural Conference at Vienna, meteorologists were quite at sea as to how these sums of temperature were to be calculated.

The credit of solving this problem belongs to Lieut.-General Richard Strachey, the Chairman of the Meteorological Council. In the first place he proposes to adopt a certain unit of temperature to supply a standard for calculation, the unit being one degree continued for the unit of time, either one hour or one day, as the case may be. Such a unit may be conveniently called an hour degree, or day degree. The unit of time adopted for the calculations to which $I$ am about to refer is a day, and the unit of what may be termed the effective temperat ure is therefore $a$ day degree. A day degree therefore signifies $\mathbf{I}^{\circ} \mathrm{F}$. of excess or defect of temperature above or below $42^{\circ} \mathrm{F}$. continued for twenty-four hours, or any other number of degrees for an inversely proportional number of hours.

Now the first idea I want you to take in about these day degrees is that when we speak generally of the mean or average temperature for a day, or month, or year, we imply that the resulting temperature is the same as would be observed if the thermometer indicated this mean temperature throughout the entire period for which the mean is taken. Thus, if we were dealing with daily means, an average daily temperature of $62^{\circ} \mathrm{F}$., which is an ordinary temperature for a warm summer's day, would mean twenty day degrees of temperature for that day, starting from the assumed base line of $42^{\circ} \mathrm{F}$., which has already been mentioned.

The first step therefore towards determining this effective temperature in day degrees resolves itself into determining as speedily and simply as possible the average temperature for the period under consideration.

We have, fortunately, to our hands, a very simple mode of arriving at the mean temperature with accuracy sufficient for our purposes. Almost all observers record the maximum and mininum temperatures once in the twenty-four hours. It is found that the half sum of these readings, the mean between them, is nearly but not exactly the average for the day. It must, of course, be understood that the instruments must be read regularly and at the same hour every day.

The next points which require attention are: whether the maximum and minimum are both above $42^{\circ}$, which occurs in summer, or both below that point, which occurs in winter; or, finally, whether one is above, and the other below. In the first case all the accumulated temperature is to the good; it is all on the positive side. In the second case it is all on the negative side. The third case is the only one which presents difficulty, for when the extreme temperatures are on either side of the line of $42^{\circ}$, one portion of the effective temperature for the day is poitive, and the other negative.

Now, General Strachey carried out a long series of calculations, based on the observed hourly temperatures at Kew Observatory, and at other stations in the United Kingdom, in order to ascertain the magnitude of the co-efficient by which the difference between either of these extreme temperatures and the base temperature $\left(42^{\circ} \mathrm{F}\right.$.) should be multiplied in order to obtain the values of the temperatures in excess or defect of $42^{\circ} \mathrm{F}$. expressed in day-degrees, and he found that this, for a weekly period, was 0.4 .

Accordingly we get the following rules:-

If the mean of the day is above $42^{\circ} \mathrm{F}$., we multiply the difference between the minimum and $42^{\circ} \mathrm{F}$. by $0^{\circ} 4$ (four-tenths), and call this the negative effective temperature.

To find the positive effective temperature we subtract from the difference between the mean for the day and $42^{\circ}$, the negative effective temperature just determined.

If the mean of the day is below $42^{\circ} \mathrm{F}$. the proceeding is similar; but we first ascertain the positive effective temperature, and subtract that from the difference between $42^{\circ} \mathrm{F}$. and the mean, thus obtaining the negative effective temperature. 
The method of determining the effective temperature, which may briefly be called the accumulated temperature, is fully explained in a paper by General Strachey, which will appear in the forthcoming volume of the "Quarterly Weather Report," that for 1878 . Meanwhile it is extremely interesting to examine the diagrams in the Annexe somewhat minutely, and to observe how the total accumulated temperature, say, up to July $\mathbf{I}$, is made up in very different ways in the two years, I88I and I884, there exhibited.

The year 1881 was very cold in the winter, and its accumulated temperature was made up in the spring and early summer. In the present year we had practically no frost, but then we had unusually cold weather at Easter and at the end of May.

The practical application of the data thus obtained as standards of comparison for the growth and ripening of various agricultural products must of course be left to the agriculturists, and it will be interesting to learn how far a correspondence between the character of the several crops and the accumulated temperature of the year can be established.

The measure of temperature afforded by this system of computation appears to be as well suited to supply a standard of comparison of climates for hygienic purposes as for agriculture, and the diagrams indicate in a forcible manner the characteristic differences of climate, in respect of temperature, of the portions our islands to which they refer.

Mr. William Marriott read a paper on "Some Occarional Winds and their Influence on Health." After referring briefly to the causes of winds, Mr. Marriott spoke of the East wind, the Mistral, the Sirocco, and other well-known occasional winds. Of the East wind, Mr. Marriott said it was the most dreaded in this country. It is usually dry, cold, and very penetrating, and is well described in the old saying-

$$
\text { "When the wind is in the East }
$$$$
\text { 'Tis neither good for man nor beast." }
$$

Dr. Arthur Mitchell, in a "Note on the Weather of 1867 , and on some effects of East winds," says, "Such winds blowing over a moist surface, like that, for instance, of the human body, tend to reduce the temperature of that surface to the temperature of evaporation, which in this case is much below that of the air itself. In licking up the moisture - that is, in causing its evaporation - a large amount of heat is rendered latent. This heat must be taken from something, and, in point of fact, our bodies are, and must be, atmost its entire sonrce. A cold and dry wind, therefore, cools the surface of our bodies, not simply by enveloping them in a cool medium, and warming itself by conduction at their expense. It does this of course; but, being dry as well as cold, it does it with less activity than it would if moist and cold--damp air being a better conductor than dry air. It is chiefly, however, by the other mode that dry cold winds abstract heat from our bodies, - that is, by using their heat in the conversion of moisture into vapcur. The heat so used becomes latent, and is for the time being lost. It does not raise the temperature of the air in immediate contact with the body, On the contrary, that air itself, low as its temperature may be, gives up some of its heat to become latent in the vaporised moisture, and probably gives up more than it gains from our bodies by conduction, so that the temperature of the film of air actually in contact with our bodies may be, and probably is, a little lower than the temperature of the bulk. The quantity of heat which our bodies lose in this way is far from insignificant, and the loss cannot be sustained without involving extensive and important physiological actions, and without influencing the state of health. In feeble and delicate constitutions, the resources of nature prove insufficient to meet the demand made on them, and a condition of disease then ensues.' - (Journal of the Scottish Meteorological Society, vol. ii. p. 8o.)

\section{SCIENTIFIC SERIALS}

Proceedings of the Linnean Socicty of New South Wales, vol. viii. part iv. contains :-Occasional notes on plants indigenous in the neighbourhood of Sydney, by E. Haviland.-Temperature of the body of Echidna hystrix, by N. de MiklouhoMaclay.-Plagiostomata of the Pacific, part 2, by N. de Miklouho-Maclay and W. Macieay, F.L.S.-Notes on some reptiles of the Herbert River, by W. Macleay, F.L.S.- -Notes on some customs of the aborigines of the Albert district, by C.
S. Wilkinson, F.G.S., F.L.S.-On the brain of Grey's whale, by W. A. Haswell, M.A., B.Sc.-On a new genus of fish from Port Jackson, by W. Macleay, F.L.S.--Fishes from the South Sea Islands, by Charles De Vis, M.A.--Some results of trawlfishing outside Port Jackson, by W. Macleay, F.L.S.-The "Barometro Araucano" from the Chiloe Islands, by N. de Miklouho-Maclay. - Far southern localities of New South Wales plants, by Baron Sir F. von Müller, K.C.M.G., F.R.S.-Description of Australian Micro-lepidoptera, part 10, by E. Meyrick, B.A.-Notes on the geology of the southern portion of the Clarence River basin, by Prof. Stephens, M.A.-Dimensions of some gigantic land-tortoises, by J. C. Cox, M.D., F.L.S.

THE Zeitschrift für zuissenschaflliche Zoologie, vol. xl, part I, contains :-P. M. Fischer, upon the structure of Opisthotrema cochleare, nov. genus et spec. : a contribution to the anatomy of the Trematoda. $-F$. Blochmann, remarks upon some Flagellates. $-\Lambda$. Korotneff, the budding of Anchinia. - L. Döderlein, studies of Japanese Lithistidæ.-J. Brock, the male of Sepioloidea lineolata, d'Orb. (Sepiola lineolata, Quoy and Gaim), with general remarks upon the family of Sepioladx.-A. Gruber, upon the nucleus and nuclear-fission in the Protozoa.-O. E. Imhof, results of a study of the pelagic fauna of the Swiss fresh-water lakes and tarns.

Part 2 contains:-A. Kölliker, the embryonic germinal layers and tissucs (with a postscript).-C. R. Hoffmann, contribution to the history of the development of reptiles.-P. Langerhans, the worm-fauna of Madeira, - F. Ahlborn, ( $\mathrm{I}$ ) upon the origin and exit of the cerebral nerves in Petromyzon; (2) upon the segmentation of the body in Vertebrates; (3) upon the importance of the pineal gland (conarium, epiphysis cerebri). -C. Emery, study of Luciola italica, L.

Tre Morphologisches Fahrbuch, vol. ix. part 3, contains the following :-G. Ruge, contributions to the study of the hremal system in man.-J. E. V. Boas, a contribution to the morphology of the nails, claws, and hoofs of the Mammalia.-M. Davidoff, on the variations of the plexus lumbosacralis of Salamandra maculosa.-O. Buitschli, remarks upon the gastræa theory.-C. Gegenbaur, on the accessory tongue (Plica fimbriala) of man and other mammals.

Vol. ix. part 4 contains :-M. Sagemehl, contributions to the comparative anatomy of fishes, ii., some remarks upon the membranes of the brain in bony fishes.-P. Lesshaft, upon the muscles and fasciæ of the female perineum. - H. Klaatsch, contributions to a more exact knowledge of the Campanularia.-G. Baur, the carpus of the Artiodactyles : a morphogenetic study.-G. Gegenbaur, contributions to the anatomy of the mammary organs in Echidna.

\section{SOCIETIES AND ACADEMIES EDINBURGH}

Mathematical Society, July 1r.-Dr. R. M. Ferguson in the chair.- Prof. Chrystal contributed three papers on the application of the multiplication of matrices to prove a theorem in spherical geometry, on the discrimination of conics enveloped by rays joining the corresponding points of two projective ranges, and on the partition of numbers ; in connection with the second of these he indicated a solution he had received in a note from Signor Cremona of Rome.-Dr. Alexander Macfarlane gave illustrations of a common error in geological calculations; and Mr. A. Y. Fraser explained two solutions (by himself and Mr. R. E. Allardice) of a problem of arrangements entitled La Tour d'Hanoï, which appeared in the Fournal des Débats for December $27,1883$.

\section{PARIS}

Academy of Sciences, July 28.-M. Rolland, President, in the chair.-On the rule of Newton as demonstrated by SyIvester; a sequel to the two previous communications, by $M$. de Jonquières. Here two cases of indeterminants are dealt with : (I) That in which several consecutive terms are wanting in the equation, the absence of one or more non-consecutive terms giving rise to no uncertainty; (2) that in which one or more of the quadratic functions intervening in the operation are identically nul. - A study of the deviations of the pendulum at Fort Loreto, Puebla, Mexico, two illustrations, by M. Bouquet de la Grye. These observations were conducted by means of a multiplying seismograph set up in connection with the expedition sent out to observe the transit of Venus. Their object was 